\title{
Secondary Abdominal Compartment Syndrome Recognized in Operating Room in Severely Injured Patients
}

\author{
Seok Hwa Youn, M.D., John Cook-Jong Lee, M.D., Ph.D., Kyoungwon Jung, M.D., Ph.D., Jonghwan Moon, M.D., \\ Yo Huh, M.D., and Younghwan Kim, M.D., Ph.D.
}

Division of Trauma Surgery, Department of Surgery, Ajou University School of Medicine, Suwon, Korea

For trauma patients with severe shock, massive fluid resuscitation is necessary. However, shock and a large amount of fluid can cause bowel and retroperitoneal edema, which sometimes leads to abdominal compartment syndrome in patients without abdomino-pelvic injury. If other emergent operations except intraabdomen are needed, a distended abdomen is likely to be recognized late, leading to multiple organ dysfunction. Herein, we report two cases of a 23-year-old woman who was in a car accident and a 53-year old man who was pressed on his leg by a pressing machine; severe brain swelling and popliteal vessel injury were diagnosed, respectively. They were both in severe shock and massive fluid resuscitation was required in the emergency department. Distended abdomen was recognized in both the female and male patients immediately after neurosurgical operation and immediately before orthopaedic operation in the operating room, respectively. Decompressive laparotomy revealed massive ascites with retroperitoneal edema.

Key Words: abdominal compartment syndrome; shock; trauma.

Attention to and studies about intra-abdominal hypertension has increased, especially since World Society of Abdominal Compartment Syndrome established consensus definitions. The conference defined the abdominal compartment syndrome (ACS) as a sustained intra-abdominal pressure $>20 \mathrm{mmHg}$ (with or without an abdominal perfusion pressure $<60 \mathrm{mmHg}$ ) that is associated with new organ dysfunction/failure.[1] As for trauma, ACS can develop in patients who have abdominopelvic or retroperitoneal injuries. The outcomes of this ACS from direct injuries have been improved after introduction of damage-control surgery and liberal application of open abdomen.[2] However, even in patients with severe shock without injuries of abdomino-pelvic region, ACS can also develop. Here, we report two cases of severely injured patients who required neurosurgical operation and vascular with orthopaedic operation respectively. There were no abdomino-pelvic injuries in both cases.

Received on December 8, 2015 Revised on February 15, 2016 Accepted on February 18, 2016

Correspondence to: Younghwan Kim, Division of Trauma Surgery, Department of Surgery, Ajou University School of Medicine, 206 World cup-ro, Yeoungton-gu, Suwon 16499, Korea

Tel: +82-31-219-4457, Fax: +82-31-219-7765

E-mail: galgunbam2@daum.net

*No potential conflict of interest relevant to this article was reported.

\section{Case Report}

\section{Case 1}

A 23-year-old Korean woman was transferred from the accident scene to our emergency department undergoing a cardiopulmonary resuscitation because of a passenger accident in a sports utility vehicle 30 minutes ago. On arrival her

(cc) This is an Open Access article distributed under the terms of the Creative Commons Attribution Non-Commercial License (http://creativecommons.org/ licenses/by-nc/3.0/) which permits unrestricted non-commercial use, distribution, and reproduction in any medium, provided the original work is properly cited. Copyright (c) 2016 The Korean Society of Critical Care Medicine 

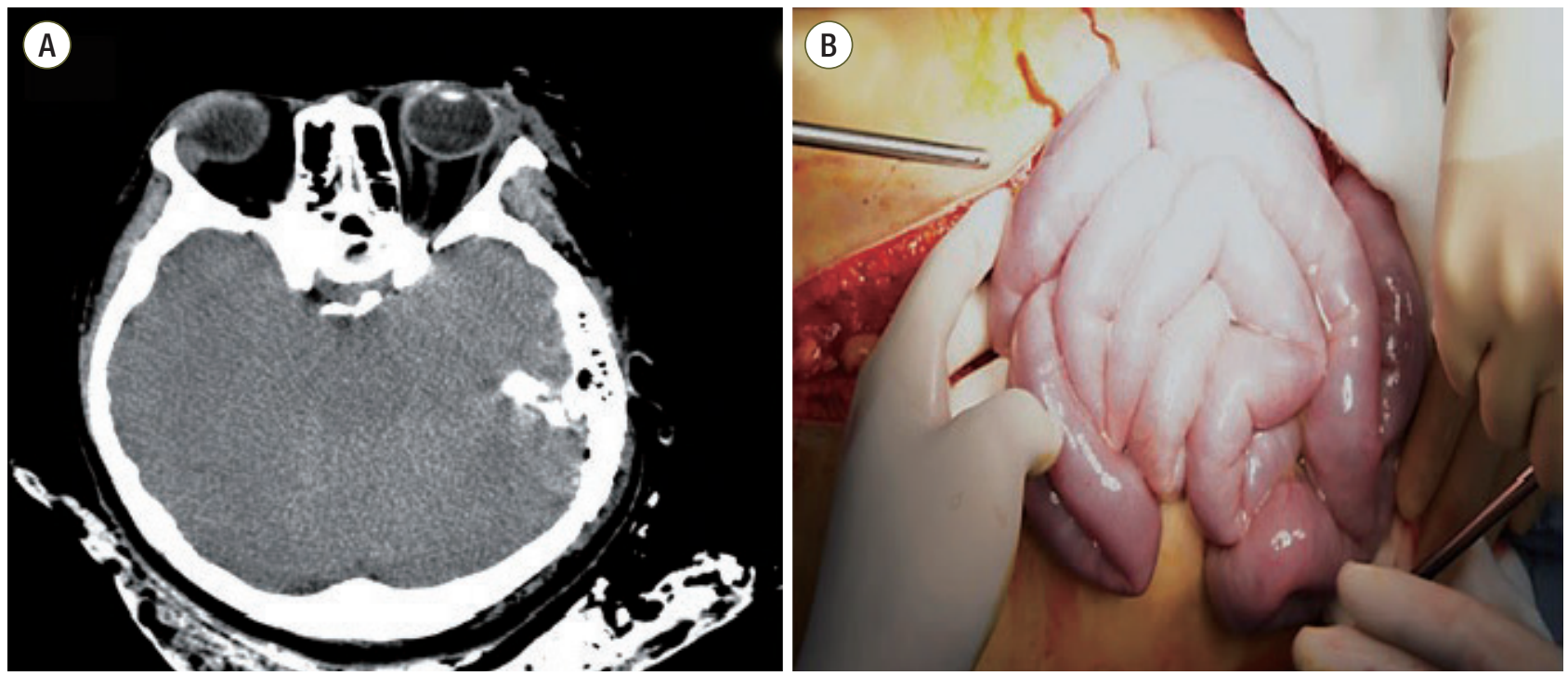

Fig. 1. Brain computed tomography scan shows severe brain edema $(A)$ and bowel edema without no hemorrhage in abdominal cavity was observed (B).

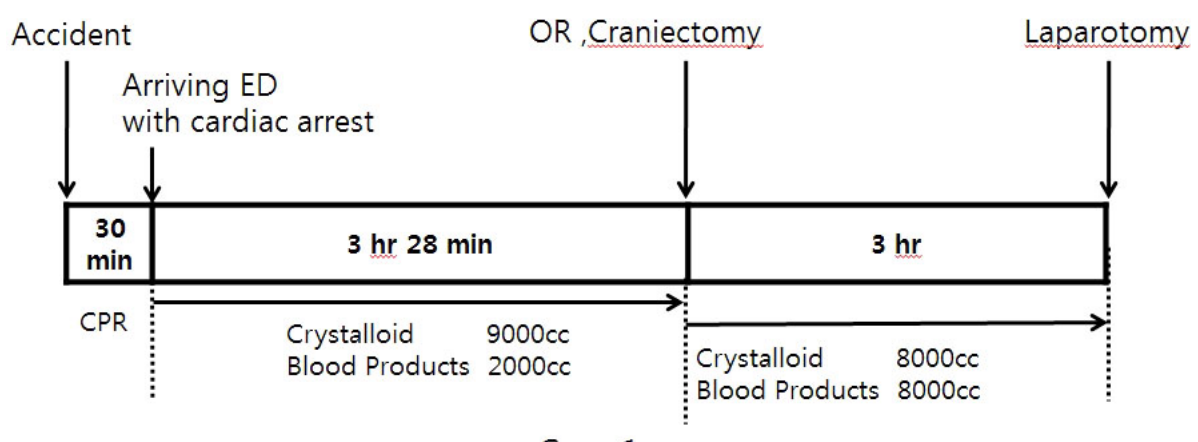

Case 1
Fig. 2. A time table until recognizing abdominal compartment syndrome in operating room. ED: emergency department, OR: operating room, CPR: cardiopulmonary resuscitation. blood pressure was not checked and cardiac massage was continuously performed. The recovery of spontaneous circulation was achieved after 3 minutes' cardiopulmonary resuscitation. Massive fluid resuscitation was required due to persisting hypotension. Body temperature was too low to be checked. Arterial blood gas analysis showed a pH of 6.978 . Computed tomography scans showed multiple skull fracture lines and severe brain swelling with left temporal bone fracture (Fig. 1). Right pneumothorax was also detected. However, there was no abdominal or retroperitoneal injury. The injury severity score was 34 points. Emergent craniotomy was performed. During craniotomy, the vital sign was unstable and disseminated intravascular coagulopathy caused much bleeding. She was received about 17,000 cc of crystalloid fluid and 10,000 cc of blood products during resusci- tation and craniotomy (Fig. 2). Just after craniotomy, severe abdominal distention was recognized in operating room (OR) and intraabdominal pressure was measured by transbladder technique in which $25 \mathrm{~mL}$ of saline was instilled into the bladder via the Foley catheter and water manometer was connected and placed at the level of pubic symphysis. It revealed $44 \mathrm{mmHg}$. Emergent laparotomy was performed under the diagnosis of ACS, which was 7 hours and 17 minutes after accident. Bowel edema and lots of watery fluid in abdominal cavity and from retroperitoneum were observed (Fig. 1). There was no bleeding or injury of intraabdominal organs. The measured serum protein/albumin was 4.8/2.1 g/ dL. Despite of intensive care, brain progressively swelled to death on hospital day 5 . 

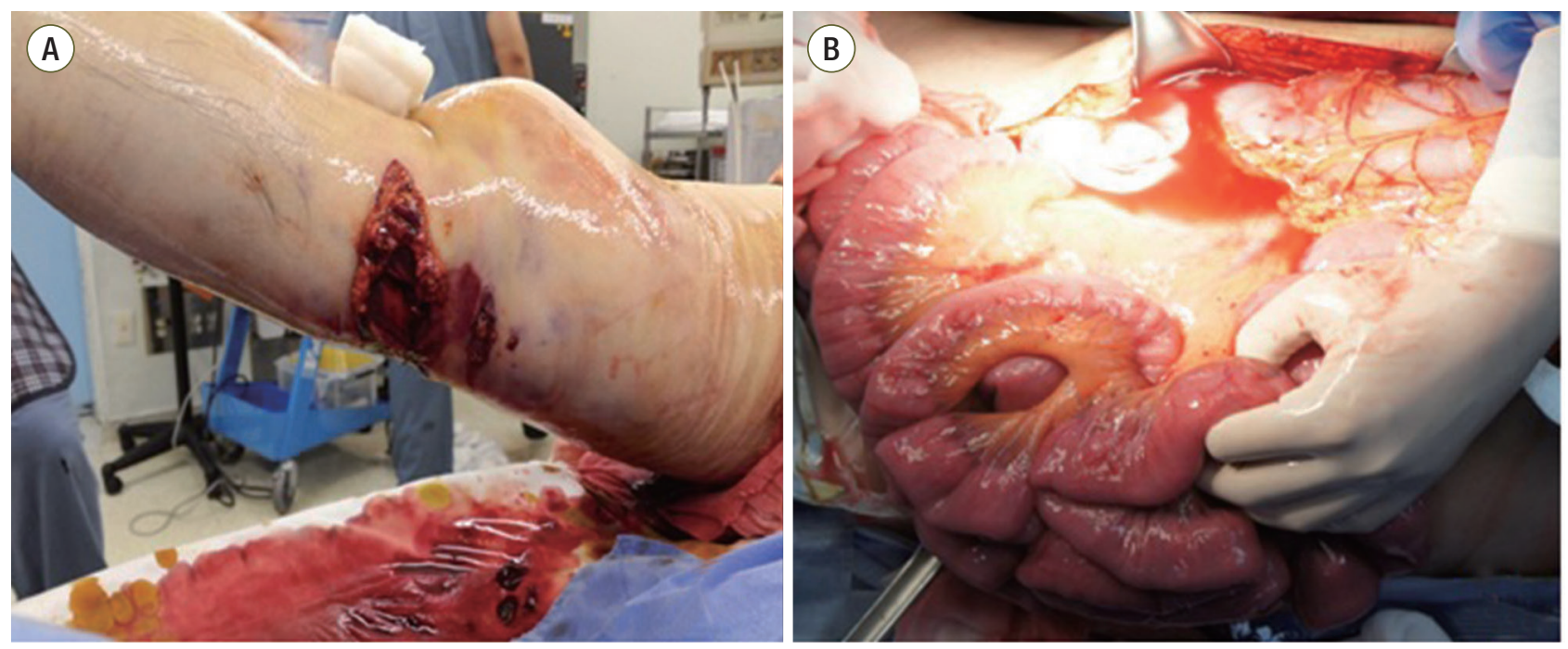

Fig. 3. Severe shock was caused by popliteal vessel injury (A) and laparotomy shows lots of ascites (B).

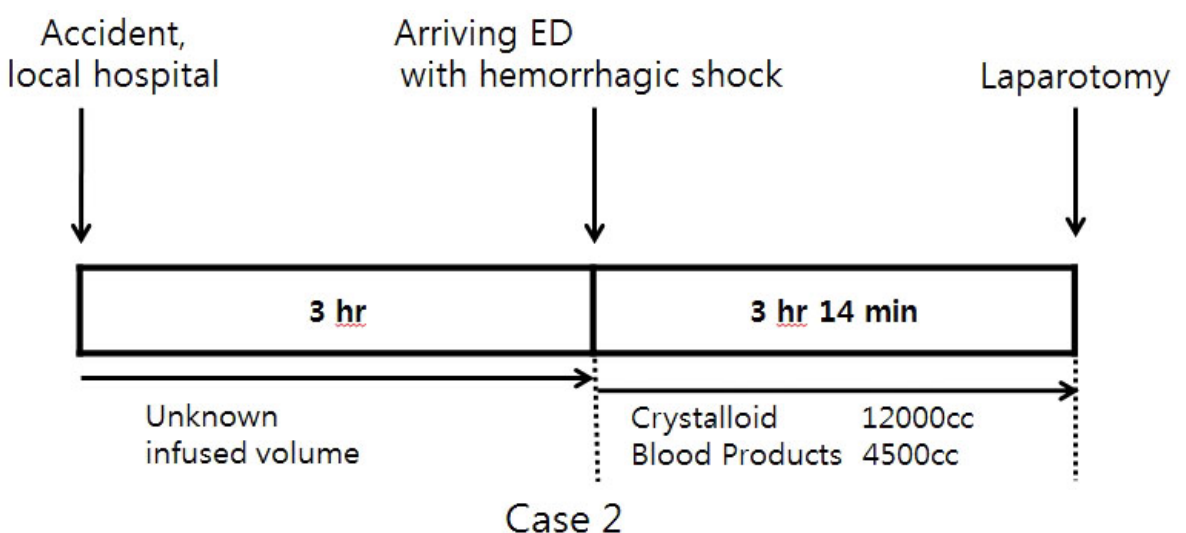

Fig. 4. A time table until recognizing abdominal compartment syndrome in operating room. ED: emergency department.

\section{Case 2}

A 53-year-old Korean man was admitted after 3 hours of the accident in which his right leg was pressed by pressing machine. In our emergency department, his initial vital sign was as follows; blood pressure $60 / 40 \mathrm{mmHg}$, pulse rate was 121 beats/min, respiratory rate was $18 / \mathrm{min}$ and body temperature $35.9^{\circ} \mathrm{C}$. Arterial blood gas analysis showed a $\mathrm{pH}$ of 7.195 . The diagnosis was comminuted open fracture of right distal femur with rupture of popliteal artery and vein (Fig. 3). The injury severity score was 18 points. Compressive hemorrhagic control by tourniquet wasn't very effective and $12,000 \mathrm{cc}$ of crystalloid was infused before operation with 3 packs of fresh frozen plasma and 16 units of packed red blood cell (pRBC) due to sustained shock (Fig. 4). His serum protein/albumin level before surgery was $1.9 / 1.5 \mathrm{~g} / \mathrm{dL}$. During preparation for general anesthesia for orthopaedic and vascular surgery in OR, abdominal distention was recognized. Abdominal pressure via trans-bladder technique revealed $48 \mathrm{mmHg}$ and emergent laparotomy was performed first, which was 7 hours after accident. Massive watery fluid, retroperitoneal edema and moderate bowel edema were observed (Fig. 3). Abdominal and retroperitoneal injury was not detected. A closure of abdominal wall was performed after 3 days of the primary surgery, and he was transferred to general ward in intensive care unit day 37. He was discharged on hospital day 256.

\section{Discussion}

According to the definitions of 2013 World Society of 
Abdominal Compartment Syndrome, ACS is classified into three types: primary ACS, secondary ACS and recurrent ACS.[3] Primary ACS is related to the injury or disease in the abdomino-pelvic region and recurrent ACS is the condition in which it develops following previous surgical or medical treatment of primary or secondary ACS. However, secondary ACS refers to the conditions that do not originate from the abdomino-pelvic region. It is relatively elusive and easy to miss

The first case of secondary ACS was reported by Burrows et al. but Maxwell et al. first used the term in their report of six cases.[4,5] The patients of secondary ACS usually have severe injury resulting in shock and require massive fluid resuscitation. Although secondary ACS is difficult to identify its exact prevalence, Balogh et al.[6] reported even $9 \%$ of 128 patients who sustained severe injuries with severe shock and required aggressive shock resuscitation. Some independent risk factors have been reported: massive crystalloid fluid resuscitation ( $>5,000 \mathrm{~mL}$ in 24 hours), multiple transfusions ( $>10$ units of pRBC in 24 hours), hypothermia (core temperature $<33^{\circ} \mathrm{C}$ ), base deficit/acidosis $(\mathrm{pH}<7.2)$ and body mass index $(>30)$. $[3,7,8]$

The crucial pathophysiology of secondary ACS is ischemia/reperfusion injury. Severe shock leads to whole body ischemia and bowel is pretty vulnerable to ischemia. Resuscitation with massive fluid results in reperfusion of bowel wall and bowel edema rapidly progresses. Increased abdominal pressure again hampers the lymphatic drainage of bowel, which aggravates the bowel edema.[8] Capillary leak syndrome (CLS) with increased hydrostatic pressure is also major pathophysiology of increased abdominal pressure. In severely injured patients, systematic inflammatory response resulted from shock and local injured tissue or organs causes increased permeability of the capillary.[9] In 1960, Clarkson et al.[10] reported this was a rare syndrome and a lifethreatening condition. However, in $131^{\text {st }}$ Annual Meeting of American Surgical Association, it was reported that 21\% of severe trauma patients who were admitted in intensive care unit had trauma induced CLS.[11] Many cytokines like interleukin-1, interleukin-6 and tumor necrosis factor- $\alpha$ act in this phenomenon.[7] In that situation, massive crystalloid fluid increases the hydrostatic pressure and lowers the oncotic pressure. Massive ascites from retroperitoneum and mesentery increase the abdominal pressure with edematous bowel.

In our two cases, they suffered from severe shock and received massive fluid resuscitation. In each case, the shock was caused by brain injury and vessel injuries of lower extremity respectively. Though there was no abdominopelvic injury or retroperitoneal injury, shock and massive fluid with substantial acidosis and/or low temperature might cause ACS.[3] Nowadays, haemostatic resuscitation and early transfusion has been emphasized.[12] However, especially in second case, in which bleeding was the main cause of severe shock, relatively small amount of transfusion was performed compared to crystalloid fluid. Severe shock with massive crystalloid infusion might bring about low protein/ albumin level and those low oncotic pressure could aggravate CLS.

They showed massive ascites pouring out from retroperitoneum and mesentery. Bowel edema was also observed but relatively not severe. Recognition of ACS and decompressive laparotomy were all done within 8 hours, which is relatively early.[6] It was likely that reperfusion bowel injury and lymphatic flow obstruction were not developed severely at that time. Cytokine surge resulting in increased capillary permeability with massive fluid resuscitation might be the main factor in our cases.

They were recognized in OR immediate after neurosurgical operation and immediate before orthopaedic operation respectively. Laparotomies were all performed within 8 hours. Generally in emergency department, physicians always pay attention to abdominal injury in all trauma patients. However, once a series of radiological examination exclude the abdomino-pelvic injury, physical examination for abdomen is unlikely to be done again. In this situation, if neurogurgical or orthopaedic operation is performed, missing the diagnosis of secondary ACS could happen. ACS can progress during those operations and lead to multiple organ dysfunction. One of the studies reported the mortality of secondary ACS was even 38 to $67 \%$.[8] Later recognition and decompression could explain that mortality. Fortunately in our cases, our anaesthesiologists found the distended abdomen in OR immediate after and before surgery and prompt laparotomy could resolve the ACS.

Once secondary ACS happens, it can lead to multiple organ dysfunction and thus prevention is important. Obviously, the most important prevention is a control of source 
causing shock like definitive hemorrhagic control. At the same time, minimizing crystalloid fluid as damage control resuscitation should be considered in the beginning of resuscitation.[12,13] Although it is difficult to define the volume of resuscitation being likely to cause ACS, crystalloid more than $5,000 \mathrm{~mL}$ in 24 hours is considered independent risk factor for ACS as mentioned above.[1,7] Up to now there's no standard protocol related to time interval measuring abdominal pressure in high risk patients. However, since secondary ACS is known to be early phenomenon within 1214 hours after injury, it is so important to maintain suspicion and repeat physical exam for prevention in severely injured patients who have known risk factors.[8]

In conclusion, it's important to manage shock with rapid control of source with restriction of crystalloid fluid as much as possible. All surgeons and anesthesiologist who is related to trauma should remind secondary ACS in patients who sustained severe shock required massive crystalloid volume infusion.

\section{References}

1) Malbrain ML, Cheatham ML, Kirkpatrick A, Sugrue M, Parr M, De Waele J, et al: Results from the international conference of experts on intra-abdominal hypertension and abdominal compartment syndrome. I. Definitions. Intensive Care Med 2006; 32: 1722-32.

2) Balogh ZJ, van Wessem K, Yoshino O, Moore FA: Postinjury abdominal compartment syndrome: are we winning the battle? World J Surg 2009; 33: 1134-41.

3) Kirkpatrick AW, Roberts DJ, De Waele J, Jaeschke R, Malbrain ML, De Keulenaer B, et al: Intra-abdominal hypertension and the abdominal compartment syndrome: updated consensus definitions and clinical practice guidelines from the World Society of the Abdominal Compartment Syndrome. Intensive Care Med 2013;
39: 1190-206.

4) Burrows R, Edington J, Robbs JV: A wolf in wolf's clothing--the abdominal compartment syndrome. S Afr Med J 1995; 85: 46-8.

5) Maxwell RA, Fabian TC, Croce MA, Davis KA: Secondary abdominal compartment syndrome: an underappreciated manifestation of severe hemorrhagic shock. J Trauma 1999; 47: 995-9.

6) Balogh Z, McKinley BA, Cocanour CS, Kozar RA, Holcomb JB, Ware DN, et al: Secondary abdominal compartment syndrome is an elusive early complication of traumatic shock resuscitation. Am J Surg 2002; 184: 538-43; discussion 543-4.

7) Carr JA: Abdominal compartment syndrome: a decade of progress. J Am Coll Surg 2013; 216: 135-46.

8) Balogh Z, Moore FA, Moore EE, Biffl WL: Secondary abdominal compartment syndrome: a potential threat for all trauma clinicians. Injury 2007; 38: 272-9.

9) Stein DM, Scalea TM: Capillary leak syndrome in trauma: what is it and what are the consequences? Adv Surg 2012; 46: 237-53.

10) Clarkson B, Thompson D, Horwith M, Luckey EH: Cyclical edema and shock due to increased capillary permeability. Am J Med 1960; 29: 193-216.

11) Bochicchio G, Ilahi O, Bochicchio K, Reese S, Scalea $\mathrm{T}$ : Traumatic induced capillary leak syndrome is highly predictive of mortality. 2011 April [2015 Dec 4]. Available from: http://www.americansurgical.org/files/2011/ ASA11-Program-Book-for-Web.pdf.

12) Duchesne JC, Heaney J, Guidry C, McSwain N Jr, Meade P, Cohen M, et al: Diluting the benefits of hemostatic resuscitation: a multi-institutional analysis. J Trauma Acute Care Surg 2013; 75: 76-82.

13) Duchesne JC, Barbeau JM, Islam TM, Wahl G, Greiffenstein P, McSwain NE Jr: Damage control resuscitation: from emergency department to the operating room. Am Surg 2011; 77: 201-6. 